\title{
REVIEW
}

\section{Modulation of early stress-induced neurobiological changes: a review of behavioural and pharmacological interventions in animal models}

\author{
EL Harrison $^{1,2}$ and BT Baune ${ }^{1}$
}

Childhood adversity alters the predisposition to psychiatric disorders later in life. Those with psychiatric conditions and a history of early adversity exhibit a higher incidence of treatment resistance compared with individuals with no such history. Modulation of the influence early stress exerts over neurobiology may help to prevent the development of psychiatric disorders in some cases, while attenuating the extent of treatment resistance in those with established psychiatric disorders. This review aims to critically evaluate the ability of behavioural, environmental and pharmacologic interventions to modulate neurobiological changes induced by early stress in animal models. Databases were systematically searched to locate literature relevant to this review. Early adversity was defined as stress that resulted from manipulation of the mother-infant relationship. Analysis was restricted to animal models to enable characterisation of how a given intervention altered specific neurobiological changes induced by early stress. A wide variety of changes in neurobiology due to early stress are amenable to intervention. Behavioural interventions in childhood, exercise in adolescence and administration of epigenetic-modifying drugs throughout life appear to best modulate cellar and behavioural alterations induced by childhood adversity. Other pharmacotherapies, such as endocannabinoid system modulators, antiinflammatories and antidepressants can also influence these neurobiological and behavioural changes that result from early stress, although findings are less consistent at present and require further investigation. Further work is required to examine the influence that behavioural interventions, exercise and epigenetic-modifying drugs exert over alterations that occur following childhood stress in human studies, before possible translational into clinical practice is possible.

Translational Psychiatry (2014) 4, e390; doi:10.1038/tp.2014.31; published online 13 May 2014

\section{INTRODUCTION}

Childhood adversity affects up to $40 \%$ of children raised in the West. ${ }^{1}$ Psychiatric conditions such as anxiety and depressive disorders, schizophrenia and autism spectrum disorders have each been associated with stress in childhood. ${ }^{2-6}$ The neurobiological and psychosocial implications of early adversity have also been associated with the development of other disorders in which stress plays a role, such as cardiovascular disease, type 2 diabetes mellitus and obesity. ${ }^{7-9}$

Psychiatric disorders are projected to become the second leading cause of morbidity in $2020 .^{10}$ As individuals exposed to stress in childhood display an enhanced susceptibility to these conditions, modulation of the neurobiological sequelae that result from early adversity may represent a novel target for the reduction or even prevention of chronic stress-related disorders, potentially alleviating their significant burden on the health-care system.

Animal models enable characterisation of the spectra of neurobiological alterations induced by early stress, determination of which is not possible through human studies. A number of animal models of early adversity exist. Although differing in specifics, each centres on the importance of the mother for normal development, and as such involve manipulation of this relationship. ${ }^{11}$ Animal models enable delineation of the mechanism by which a given intervention exerts its effect on a specific neurobiological change that is often not possible in clinical intervention studies.

To date, there has been no comprehensive review detailing the mechanisms and effects of interventions on the deleterious alterations in neurobiology induced by childhood stress. The objective of this review is therefore to present the current evidence in order to critically evaluate whether behavioural interventions, environmental enrichment (EE) and pharmacological interventions have properties that modulate the neurobiological alterations that result from early adversity. This review focuses on describing interventions and the mechanisms underlying their ability to modulate early stress-induced neurobiological changes using animal models. From a translational perspective, the results of this review may stimulate research in humans that were exposed to early life stress and adversity.

\section{METHODS}

The PubMed, Medline and Psychlnfo databases were searched to identify literature to conduct this review. In brief, the search was performed to identify works demonstrating modulation of changes in neurobiology induced by early stress in animal models. The search terms ('stress, psychological' [MeSH] or 'maternal deprivation' $[\mathrm{MeSH}]$ or 'maternal separation') and ('therapeutics' 
[MeSH] or 'drug therapy' [MeSH] or 'modulation' or 'intervention') and ('models, animal' [MeSH]) were used, and limits were set to articles published between 1980 and 2013 and in the English language. Reference lists were cross-referenced to locate additional works. In total, 242 full-text articles were identified after assessment of abstracts pertaining to these criteria. To determine inclusion of full-text articles within this review, animal models of early stress were restricted to those involving manipulation of the mother-pup relationship, including maternal separation, maternal deprivation, variations in maternal care and exposure to an abusive mother during childhood. Animal models examining the ability of intervention to modulate changes induced by neonatal immune challenge with lipopolysaccharide (LPS) were excluded, as were interventions that occurred exclusively before early stress exposure. Finally, 86 full-text articles were excluded on the basis of these criteria and 158 articles were included in the final analysis.

\section{ANIMAL MODELS OF EARLY LIFE STRESS}

A number of animal models of early life stress exist. Those commonly utilised include those that involve manipulation of the mother-pup relationship such as maternal separation and maternal deprivation. Paradigms differ in specifics, however generally maternal separation refers to separation of pups (either individually or as a group) from the dam for 2-6 h daily from postnatal day (PND) 14 or 21, although paradigms exist that involve separation for differing lengths of time. Maternal deprivation represents a more severe form of early life stress, and involves separating pups from the dam for a single 24-h period during early post-natal life, usually on PNDs 3 or 9 . Exposure to an abusive mother during the post-natal period represents another animal model of early life stress. ${ }^{12}$ While not early life stress per se, models that examine the impact of variations in maternal care enable characterisation of the influence low versus high levels of care exert on offspring. ${ }^{13}$ Bedding deprivation is another form of early stress, in which reduced volumes of bedding are provided to the stressed group. Stress occurs as a result of abnormal fragmented interactions with the dam due to limited bedding material. ${ }^{14}$ Disrupted long-term potentiation and decreased numbers of dendritic spines in the hippocampus, ${ }^{15}$ considered correlates for learning and memory ${ }^{16}$ and synaptic plasticity respectively, ${ }_{1}^{17}$ have been reported in models utilising bedding deprivation. Neuroendocrine alterations have also been demonstrated following bedding deprivation, with reports of elevated basal plasma corticosterone levels and reduced corticotropin-releasing hormone (CRH) mRNA expression in the hypothalamus in adulthood. ${ }^{14}$ Research is yet to assess the effect that interventions exert on changes induced by bedding deprivation; hence, such studies will not be addressed in this review.

The influence of interventions on changes in neurobiology caused by early life stress is complicated by the use of a variety of different control groups. In brief, control groups include those that are either stressed without an intervention or non-stressed with and without an intervention. Consideration of the control groups helps determine the influence a given intervention exerts under different treatment conditions.

\section{FACTORS INFLUENCING THE EFFECT OF EARLY LIFE STRESS}

The long term influence early stress exerts on neurobiology and the longevity of these changes are dependent on a number of factors. (1) The nature of early stress: as discussed previously, there are a number of animal models that involve manipulation of the mother-pup relationship (that will be discussed in depth in this review). (2) The developmental period in which stress occurs: the brain displays enhanced plasticity during times of rapid brain development, making it more vulnerable to perturbations in the environment during this time. Stress exposure during the early post-natal period, later childhood and early adolescence exerts a disproportionately large effect on the developing brain. ${ }^{18}$ (3) The duration of stress exposure and (4) the age of assessment. (5) Finally, maternal separation studies indicate that rats and mice respond differently to stress early in life; species and strains must be taken into consideration when interpreting study findings. Enhanced basal neuroendocrine reactivity has been reported in rats following maternal separation ${ }^{19,20}$ while unaltered neuroendocrine activity has been widely reported in mouse models. ${ }^{21,22}$ Similarly, rats display enhanced anxiety ${ }^{23,24}$ and depressionlike ${ }^{19,25}$ behaviours after early stress. Mixed reports exist in mice once again with unchanged behaviour in mouse models, $22,26-29$ although findings are varied. As each of these factors ultimately influences the long-term sequelae of early adversity, it is likely that they also influence the way in which interventions alter changes in neurobiology.

\section{EARLY LIFE STRESS INDUCES CHANGES IN NEUROBIOLOGY}

Although predominantly controlled by genetic factors, the nature of the early environment influences development. ${ }^{30}$ The immature nervous, endocrine and immune systems share an intertwined ontogenesis, $^{31}$ with stimulation of one during early life may ultimately impact the development of the others. ${ }^{32}$ Depending on the quality of the environment early in life, maturation is programmed along a specific axis. Stress exposure in childhood may therefore set the stage for a stress-susceptible phenotype, enhancing the predisposition to psychiatric disorder development in adulthood.

Findings from animal models of childhood adversity indicate that early stress influences behaviour, with reports of enhanced anxiety $^{23,24,33}$ and depression-like ${ }^{19,25,34-37}$ behaviour and impaired spatial learning and memory ${ }^{23,38-40}$ after early stress. At present, the specific neurobiological changes underlying these behavioural changes remain to be fully characterised. Animal studies indicate that early stress exerts wide-ranging effects within the brain at a cellular level, with altered neuroendocrine activity, immune function and neurotransmission reported after early adversity. Changes often occur within specific brain regions. Studies to date have predominantly focused on the influence it exerts over the hippocampus and prefrontal cortex, although some works examine changes in the amygdala secondary to early adversity. Similarly interventional studies tend to investigate the ability of interventions to modulate changes in the hippocampus and prefrontal cortex caused by early stress; such modulatory influences will be examined in detail throughout this review.

Although inconsistencies exist across the literature, evidence suggests that early stress enhances basal hypothalamo-pituitary-adrenal (HPA) axis activity; ${ }^{19,23}$ both augmented ${ }^{41,42}$ and attenuated ${ }^{43}$ neuroendocrine responses to later stress have been shown in animal models. Impaired cell-mediated immune function has been demonstrated in both non-human primate ${ }^{44-46}$ and rodent ${ }^{47-50}$ models of early stress, alongside elevated basal proinflammatory activity. ${ }^{51}$ Reports from animal studies remain divided as to whether subsequent inflammatory responses are enhanced $^{52-54}$ or reduced ${ }^{51,54,55}$ following early stress.

Neurotransmitter systems appear vulnerable to adversity early in life. Reduced serotonin receptor expression has been demonstrated in the prefrontal cortex, ${ }^{56,57}$ hippocampus ${ }^{56,57}$ and raphe nucleus $^{22,58}$ following early stress in animal models, indicating that adversity impairs serotonergic signalling. Reports also indicate that early stress influences dopaminergic signalling; decreased activity of the mesolimbic dopaminergic system has been demonstrated following separation, once again in line with depression-like behaviour. ${ }^{58}$ Alterations in social, ${ }^{59}$ anxiety ${ }^{57}$ and depression-like ${ }^{58,60}$ behaviours have each been associated with altered monoaminergic neurotransmission in several works. Similarly decreased expression of parvalbumin, a GABAergic 


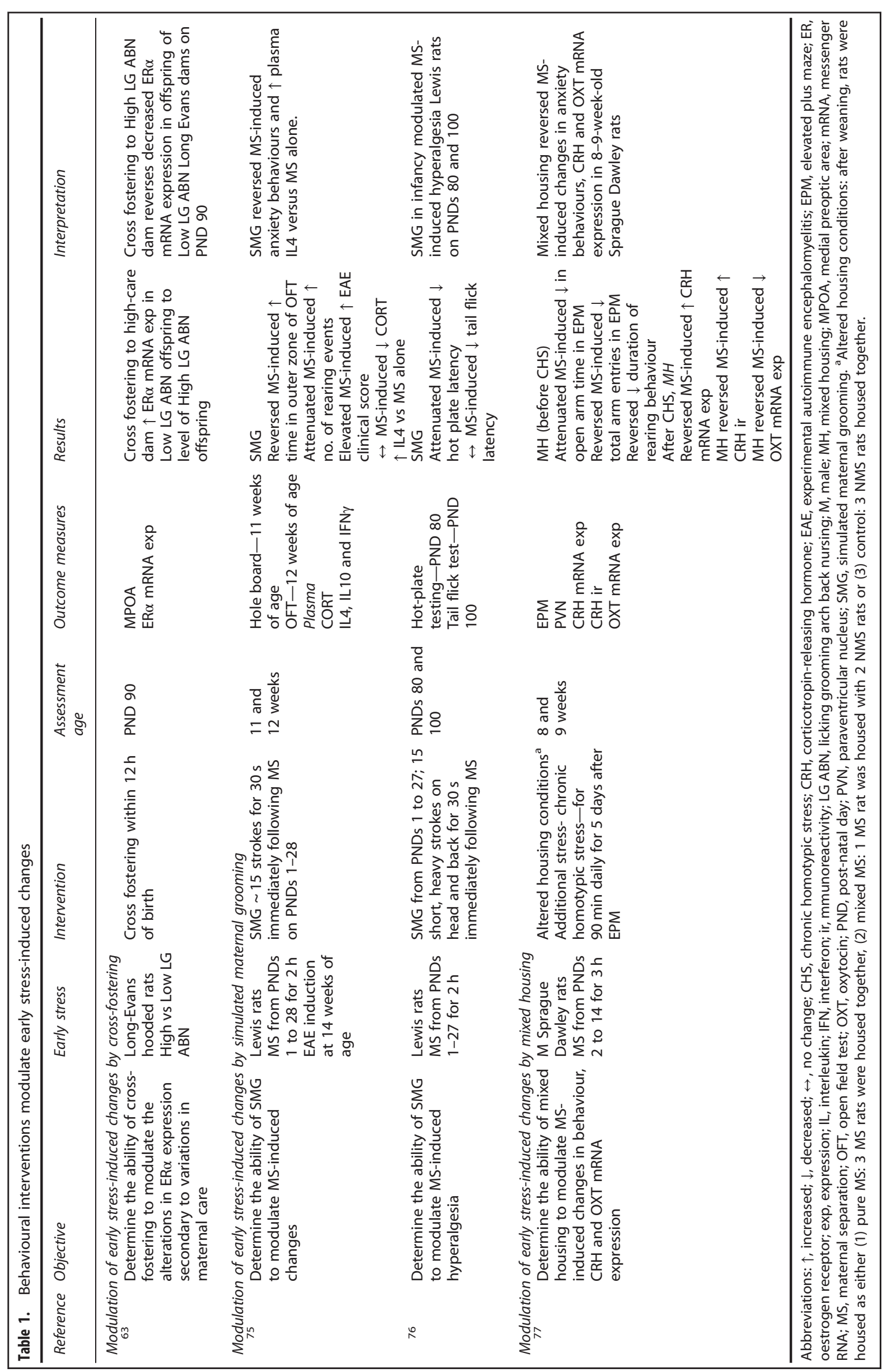


marker, has been reported in the prefrontal cortex following maternal separation, with reductions correlated with the expression of depression-like behaviour. ${ }^{60}$

\section{BEHAVIOURAL INTERVENTIONS MODULATE EARLY STRESS- INDUCED CHANGES IN NEUROBIOLOGY}

Offspring of low-care dams display lower levels of oestrogen receptor a (ERa) expression in the medial preoptic area (MPOA) compared with those raised by high-care dams. ${ }^{61}$ In the hippocampus, reduced glucocorticoid receptor (GR) expression and enhanced anxiety ${ }^{61}$ and depression-like ${ }^{62}$ behaviours have similarly been reported in offspring of low-versus high-care dams, suggesting early stress exerts its influence across a number of different brain regions. Cross-fostering (CF) of Long Evans hooded rats from low- to high-care dams within $12 \mathrm{~h}$ of birth has been shown to increase ERa expression in the MPOA of offspring on PND 90, ${ }^{63}$ indicating that enhanced levels of maternal care can influence ERa expression. Maternal behaviour is facilitated by the expression of the oxytocin receptor (OXTR) in the MPOA, 64-66 whose expression is ERa-dependent. ${ }^{13}$ In animal models, oxytocin has been shown to have a role in modulation of the neuroendocrine stress axis, ${ }^{67-70}$ the expression of anxiety-like behaviour ${ }^{71}$ and pain perception. ${ }^{72,73}$ Alterations in OXTR expression secondary to variations in maternal care may therefore influence the stress axis, behaviour and pain perception.

Sprague Dawley rats exposed to stroking on PND 10 exhibit enhanced oxytocin concentrations in the hypothalamus compared with non-stroked controls, ${ }^{74}$ prompting investigation into the ability of simulated maternal grooming (SMG) to modulate behavioural changes induced by maternal separation. SMG, the application of short, heavy strokes on the head and back for $3 \mathrm{~s}$ immediately following maternal separation for the first month of life reversed separation-induced anxiety behaviours in Lewis rats in adulthood. ${ }^{75}$ Serum corticosterone concentrations were unaltered by maternal separation, ${ }^{75}$ preventing characterisation of the influence SMG exerted on the neuroendocrine stress response, however indicating that SMG did not exert its beneficial effect by modulating neuroendocrine activity. Attenuation of separationinduced hyperalgesia has also been reported following SMG from PNDs 1 to 27, as indicated by increased hot-plate latencies in SMGtreated Wistar rats compared with control. ${ }^{76}$ Similarities exist between the influence SMG exerted over the stress axis and pain perception and the role of oxytocin within the brain. As such, it may be that SMG exerted its modulatory effect via influencing central oxytocinergic signalling, although oxytocin concentrations were not quantified in this study. ${ }^{76}$

Mixed housing $(\mathrm{MH})$ involves communal housing of separated and non-separated animals in the same cage from the time of weaning, and has been shown to attenuate enhanced anxiety behaviours following maternal separation in male Sprague Dawley rats. ${ }^{77}$ Following administration of chronic homotypic stress, MH also reversed the increased CRH mRNA expression and immunoreactivity in the hypothalamus induced by early stress at 8-9 weeks of age. ${ }^{77}$ Similar reversal of stress-induced changes in hypothalamic oxytocin mRNA expression was also noted in separated rats housed in mixed conditions. ${ }^{77}$ Together these findings suggest that $\mathrm{MH}$ may exert its modulatory effect on behaviour by reducing $\mathrm{CRH}$ and enhancing oxytocin expression within the hypothalamus, thereby decreasing the magnitude of the HPA response to subsequent stress.

Whilst SMG and MH differ in specifics, each centres on enhancing the level of care provided during childhood. The similarities between the modulatory effects of these interventions with the roles of oxytocin within the central nervous system, including in the expression of maternal behaviour, suggest that these interventions may act via enhancing oxytocin signalling within the brain. Additional studies are required to quantify central oxytocin and OXTR expression levels in response to such interventions to ascertain whether these behavioural interventions influence oxytocin expression in animal models of early stress (Table 1).

\section{EXERCISE MODULATES EARLY STRESS-INDUCED CHANGES}

Evidence is beginning to emerge indicating that exercise may have an important role in the prevention and treatment of psychiatric disorders ${ }^{78}$ and may attenuate age-related cognitive decline. ${ }^{79}$ This is of interest given the association between early life stress and the development of disorders such as depression later in life. Enhanced neuroplasticity has been shown in response to exercise, with changes often dependent on the type of exercise performed. Aerobic and resistance training have recently been reported to increase neuroplasticity to a greater extent compared with other subtypes of exercise. ${ }^{80}$ Results from a meta-analysis indicate that exercise can improve cognitive performance in older adults ( 0.5 s.d. on average), irrespective of the nature of cognitive task, type of exercise or participant characteristics. ${ }^{79}$ Taken together, findings suggest that enhanced neuroplasticity may be associated with functional improvement.

Exercise from PNDs 25 to 68 attenuated the increased immobility times in the forced swim test (FST) displayed by maternally separated Sprague Dawley rats compared with control from PND 26, suggesting reduced depression-like behaviour following intervention. The modulatory influence of exercise also appears to extend to other behaviours influenced by early stress in animal models. Maternally separated Sprague Dawley rats exercised from PNDs 21 to 30 exhibited improved long-term memory capability and spatial learning, as indicated by improved performance in the step-down latency and radial arm maze tasks compared with their non-exercised counterparts. ${ }^{82}$ Reports indicate that early stress can suppress the serotonin system ${ }^{83,84}$ and the role serotonin has in modulation of neural stabilisation and behavioural impairment. ${ }^{85}$ While not a modulatory effect per se, exercise also enhanced serotonin synthesis and tryptophan expression in the hippocampus and dorsal raphe nuclei in both separated and non-separated Sprague Dawley rats ${ }^{82}$ alongside behavioural changes. Taken together, modulation of both serotonin expression and behaviour by exercise suggests that the positive influence exercise exerts may be partially attributable to its ability to alter the serotonergic system and the role it has in neural connectivity and behaviour.

Additional insight into the mechanisms by which exercise exerts its beneficial effect over early stress-induced changes in neurobiology comes from research examining modulation of cellular changes following maternal separation. Sprague Dawley rats exercised over a 6-week period in adulthood (from PNDs 40 to 82) following maternal separation from PNDs 2 to 14 exhibited reversal of changes in 16 of 23 proteins induced by maternal separation, including those involved in neuronal structure, signalling, neurotransmission and anti-oxidative stress. ${ }^{86}$ Exercise was also reported to reduce the susceptibility of neurons to cell death previously increased by separation. ${ }^{86}$ Treadmill exercise has also been shown to enhance synaptophysin and CamKII protein expression in the ventral hippocampus of both separated and non-separated Sprague Dawley rats on PND $65 .{ }^{87}$ No differences in protein expression were noted in the dorsal hippocampus or prefrontal cortex in exercised versus non-exercised (both stressed and non-stressed), ${ }^{87}$ indicating that the effect of exercise may in fact be brain-region-specific.

Evidently, exercise modulates a number of cellular changes (such as changes in proteins involved in neuronal structure, neurotransmission, and oxidative stress and cell death) that result from early stress, indicating that it likely exerts its beneficial influence on behaviour (including depression-like behaviour, spatial learning and memory, and long-term memory capability) 
via a number of intertwined mechanisms. Considered together with its ability to modulate behavioural changes induced by early stress, it may be that exercise modulates the negative influence early stress exerts on behaviour and the later predisposition to disease by attenuating the impact childhood stress exerts on the developing brain at a structural level, potentially within the hippocampus, given that a number of behaviours modulated by exercise are known to be hippocampal-dependent.

\section{EARLY STRESS-INDUCED CHANGES CAN BE MODULATED BY ENVIRONMENTAL ENRICHMENT}

Improved dendritic arborisation, neurogenesis, synaptogenesis and long-term potentiation have been reported following EE in animal models. ${ }^{88,89}$ EE has recently been hypothesised to prevent some of the deleterious effects of stress exposure. ${ }^{90-92}$ However, only one study has addressed the ability of EE to modulate neurobiological changes induced by maternal separation to date. EE involved housing Wistar rats in groups of 7-10 in cages containing toys, wooden blocks, climbing platforms and running wheels. ${ }^{93}$ Maternally separated rats raised under conditions of EE displayed reversal of separation-induced decreases in grooming behaviour in the open field test, and attenuation of separationinduced impairments in the step-down test. ${ }^{93}$ Findings from the step-down test indicate that early stress induced a deficit in memory acquisition, consolidation or retrieval, and that this was reversed by $\mathrm{EE}$. At this stage it is unknown as to exactly how $\mathrm{EE}$ alters behavioural changes that result from early stress, however it is known to enhance neuroplasticity on a structural level. ${ }^{93}$ Findings from animal studies indicate that $\mathrm{EE}$ results in functional enhancement of neurophysiology and memory, while increasing dendritic arborisation, neurogenesis, synaptogenesis and longterm potentiation. ${ }^{88,89}$ As such, EE may modulate memory deficits induced by maternal separation by 'reprogramming' some of these same circuits in response to the enriched environment, thereby attenuating the influence early separation exerts on memory. It would be of interest for further studies to assess the ability of EE to modulate other behaviours known to be adversely effected by early stress such as anxiety and depression-like behaviours (Table 2).

\section{PHARMACOLOGICAL INTERVENTIONS CAN MODULATE THE NEUROBIOLOGICAL SEQUELAE OF EARLY STRESS}

The endocannabinoid system has an imperative role in key neurodevelopmental processes such as cell proliferation, migration and differentiation, axonal elongation and synaptogenesis. ${ }^{96-99}$ It is also considered to function as a crucial regulator of the neuroendocrine stress response. ${ }^{100}$ Recent evidence also suggests that the endocannabinoid system serves as a homeostatic neuroprotective mechanism, counteracting diverse neural insults. ${ }^{49}$ For example, administration of WIN-55, a cannabinoid agonist, has been shown to reduce neuronal loss in neonatal rats following severe asphyxia. ${ }^{101}$ Similarly, modulation of the endocannabinoid system has been shown to decrease behavioural impulsivity following maternal deprivation in adolescent rats. ${ }^{102}$

Two endocannabinoid system enhancers, arachidonoyl serotonin (AA-5HT) and OMDM-2 have been shown to modulate cellular changes within the CA1 and CA3 of the hippocampus following maternal deprivation, ${ }^{103}$ an area proposed to have a key role in mediating the behavioural effects of endocannabinoids. ${ }^{104}$ Administration of AA-5HT and OMDM-2 from PNDs 7 to 12 reduced deprivation-induced increases in glial fibrillary acidic protein (GFAP) expressed by astrocytes in Wistar rats on PND 13 compared with control. ${ }^{103}$ Attenuation of elevations in plasma corticosterone concentrations secondary to deprivation were also reported in treated male Wistar rats versus control, ${ }^{103}$ suggesting that raised corticosterone may have influenced cellular changes in the hippocampus of the male rat, and that both AA-5HT and OMDM-2 acted to reduce these changes. Similar findings have been reported in the cerebellum of maternally deprived Wistar rats, with female Wistar rats treated with $\mathrm{AA}-5 \mathrm{HT}$ or OMDM-2 displaying reduced numbers of GFAP-positive cells compared with their non-treated counterparts. ${ }^{105}$ The influence of early stress on FJC-positive cells, indicative of degenerating neuron numbers, in the cerebellum was also attenuated in male rats given AA5-HT or OMDM-2, while expression was unchanged in females. ${ }^{105}$ When considered together, it appears that the endocannabinoid system enhancers $\mathrm{AA}-5 \mathrm{HT}$ and $\mathrm{OMDM}-2$ reduce the influence maternal deprivation exerts on cellular changes within the brain in a sexdependent manner in both the hippocampus and cerebellum, possibly via altering neuroendocrine function.

To date, only one study has addressed the ability of endocannabinoid system modulators to alter behavioural changes induced by early stress. URB597 is a selective inhibitor of the enzyme fatty acid amide hydrolase, which is responsible for the breakdown of the endocannabinoid anandamide. ${ }^{102}$ Administration of URB597 from PNDs 31 to 43 results in attenuation of increases in behavioural impulsivity displayed by maternally deprived Wistar rats, ${ }^{102}$ suggesting that enhancing endocannabinoid signalling can exert beneficial effects on behaviour.

\section{ANTI-INFLAMMATORIES MODULATE EARLY STRESS-INDUCED CHANGES}

Dysfunction or loss of $\gamma$-aminobutyric acid-ergic (GABA) cells that express parvalbumin, a calcium-binding protein, have been implicated in the aetiopathogenesis of a variety of psychiatric conditions. ${ }^{106-108}$ Reduced parvalbumin expression has been reported in Sprague Dawley rats maternally separated from PNDs 2 to $20{ }^{109}$ Administration of the cyclo-oxygenase 2 (COX-2) inhibitor (NS398), a key mediator of both oxidative stress and excitotoxicity, attenuated decreases in parvalbumin expression in the prefrontal cortex of separated rats compared with vehicletreated rats upon assessment in adolescence. ${ }^{110}$ Moreover, improved working memory previously impaired by maternal separation was also reported in rats treated with NS398, as indicated by reduced errors in the win-shift maze task. ${ }^{110}$ NS398 is reported to have neuroprotective effects, and to exert a modulatory influence over excitotoxicity and neuroinflammatory insults ${ }^{111-113}$ potentially by reducing the conversion of arachadonic acid to prostaglandin, thereby reducing the multifaceted downstream effects of prostaglandins (such as induction of inflammatory mediators causing neuronal damage, ${ }^{114}$ aggravation of excitotoxic neurodegeneration ${ }^{115}$ or induction of apoptosis via stimulation of astrocytes to release glutamate $\left.{ }^{116}\right)$. As a possible mechanism of action, it can be speculated that the effects of NS398 on parvalbumin expression may therefore have been via attenuation of inflammatory changes induced by early stress, although inflammatory markers were not quantified directly in this study. In support of these suggestions is the observation that separation-induced decreases in parvalbumin expression are attenuated by the intracerebroventricular administration of the anti-inflammatory interleukin (IL) $10 .^{117}$ Moreover, a linear relationship between IL6 and parvalbumin expression in the prefrontal cortex was reported in separated rats treated with IL10, ${ }^{117}$ suggesting that the enhanced pro-inflammatory activity that persists after early stress leads to decreased parvalbumin expression in the prefrontal cortex, potentially altering the predisposition to psychiatric disease. 


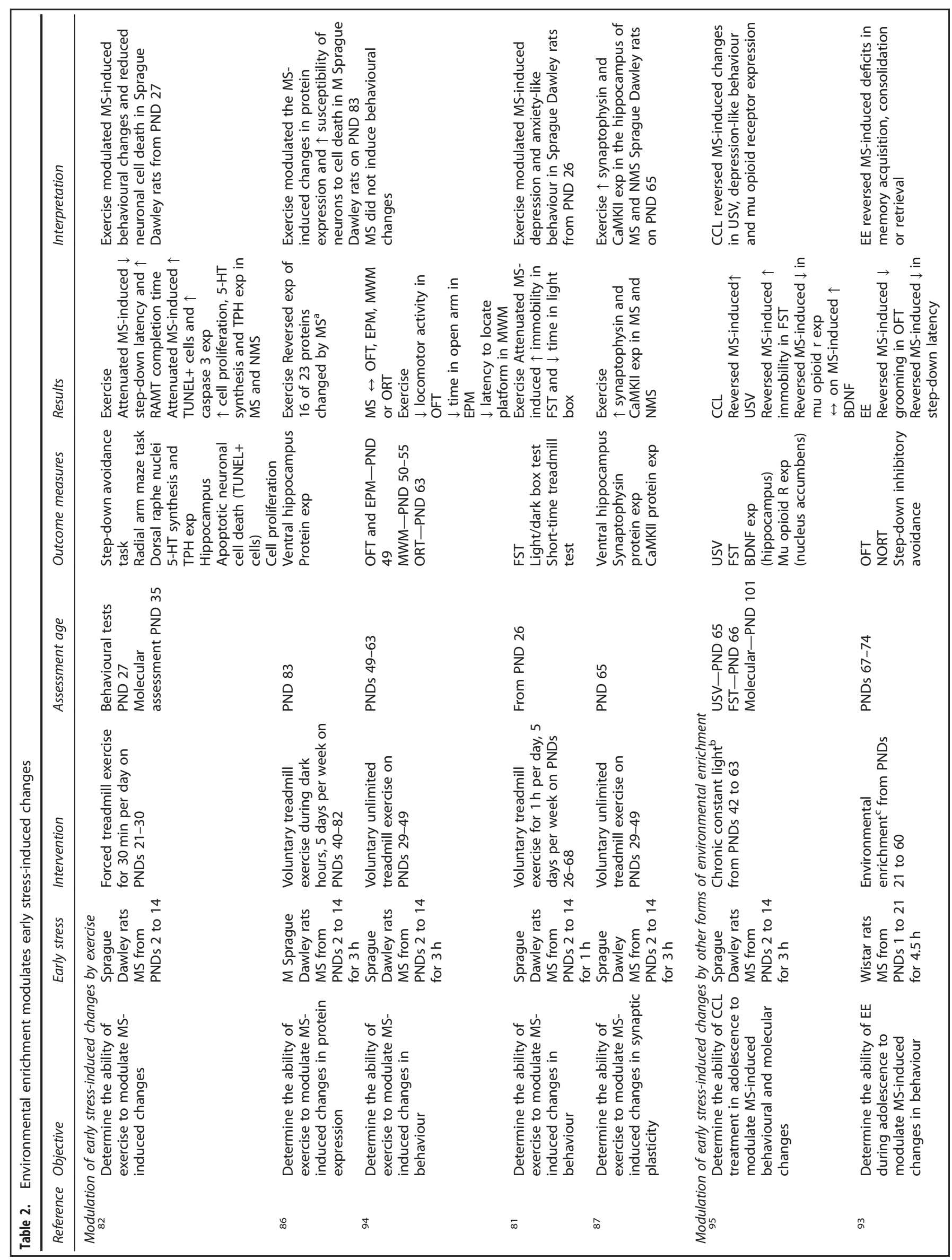




\section{MODULATION OF EARLY STRESS-INDUCED CHANGES} THROUGH ANTIDEPRESSANT ADMINISTRATION

Animal models illustrate that monoaminergic neurons such as those containing serotonin and noradrenaline are susceptible to perturbations in the early environment. ${ }^{118}$ Both serotonergic and noreadrenergic neurons are known to have critical roles in stressrelated behaviours and disorders; ${ }^{109,119,120}$ the development of psychiatric disorders such as anxiety and depressive disorders has been linked to changes in the density of these neurons. ${ }^{121-124}$

\section{Tricyclic antidepressants}

Initial studies focusing on the ability of monoaminergicmodulating drugs to alter neurobiological changes induced by early adversity centred on the use of tricyclic antidepressants (TCAs). Complete reversal of maternal separation-induced anxiety behaviours was reported in Lewis rats treated with imipramine from adolescence into adulthood. ${ }^{75}$ The authors also demonstrated attenuation of changes in experimental autoimmune encephalomyelitis clinical scores following imipramine administration. ${ }^{75}$ Similar reductions in hyperalgesia induced by maternal separation were noted in a subsequent study by this group, as indicated by improved hot-plate latencies in imipramine versus vehicle-treated rats in adulthood. ${ }^{76}$

Desipramine also appears to exert a beneficial influence over behavioural changes induced by early stress. Reduced immobility times in the FST have been shown in maternally separated Sprague Dawley rats treated with desipramine compared with vehicle-treated rats from PND 21, ${ }^{81}$ suggesting reduced depression-like behaviours in those given desipramine. Anxietylike behaviour was unaltered by desipramine, ${ }^{81}$ suggesting that its modulatory effect may be behaviour-dependent. Although speculative, it may be that desipramine exerts a greater influence over the hippocampus than over the amygdala, thereby altering depression but not anxiety-like behaviours that result from early stress. It would be of use to investigate this further in future models. Transmission of depression-like behaviour from maternally separated male C57BL/6 mice to their female offspring has recently been demonstrated. Adult male C57BL/ 6 mice maternally separated (and that displayed enhanced depression-like behaviours) as pups were bred with control females. Offspring were treated with desipramine in childhood. Compared with those treated with the vehicle, female offspring treated with desipramine displayed attenuation of depression-like behaviours in the FST. ${ }^{125}$ In contrast, desipramine administration to female offspring in adulthood did not influence depression-like behaviour, ${ }^{125}$ indicating that transgenerational transmission of depression-like behaviours are only amenable to intervention during the early post-natal period. When considered together, these studies indicate that enhanced depression-like behaviour following maternal separation, and even transgenerational transmission of these behaviours, are amenable to intervention with desipramine.

\section{Selective serotonin reuptake inhibitors}

In addition to work focusing on the modulatory effect TCAs exert on alterations induced by early adversity, a number of studies have centred on the ability of selective serotonin reuptake inhibitors (SSRIs) to alter changes that result from early stress. Maternally separated Sprague Dawley rats treated with fluoxetine in adolescence were reported to exhibit attenuation of decreases in step-down latency and increases in radial arm maze completion time compared with those treated with the vehicle. ${ }^{82}$ From a molecular perspective, this study showed that fluoxetine reduced the influence separation exerted on neuronal apoptosis in the hippocampus, while enhancing hippocampal cell proliferation on PND $35 .{ }^{82}$ As such, it is likely that fluoxetine enhanced long-term memory capability and spatial learning via increasing cell 


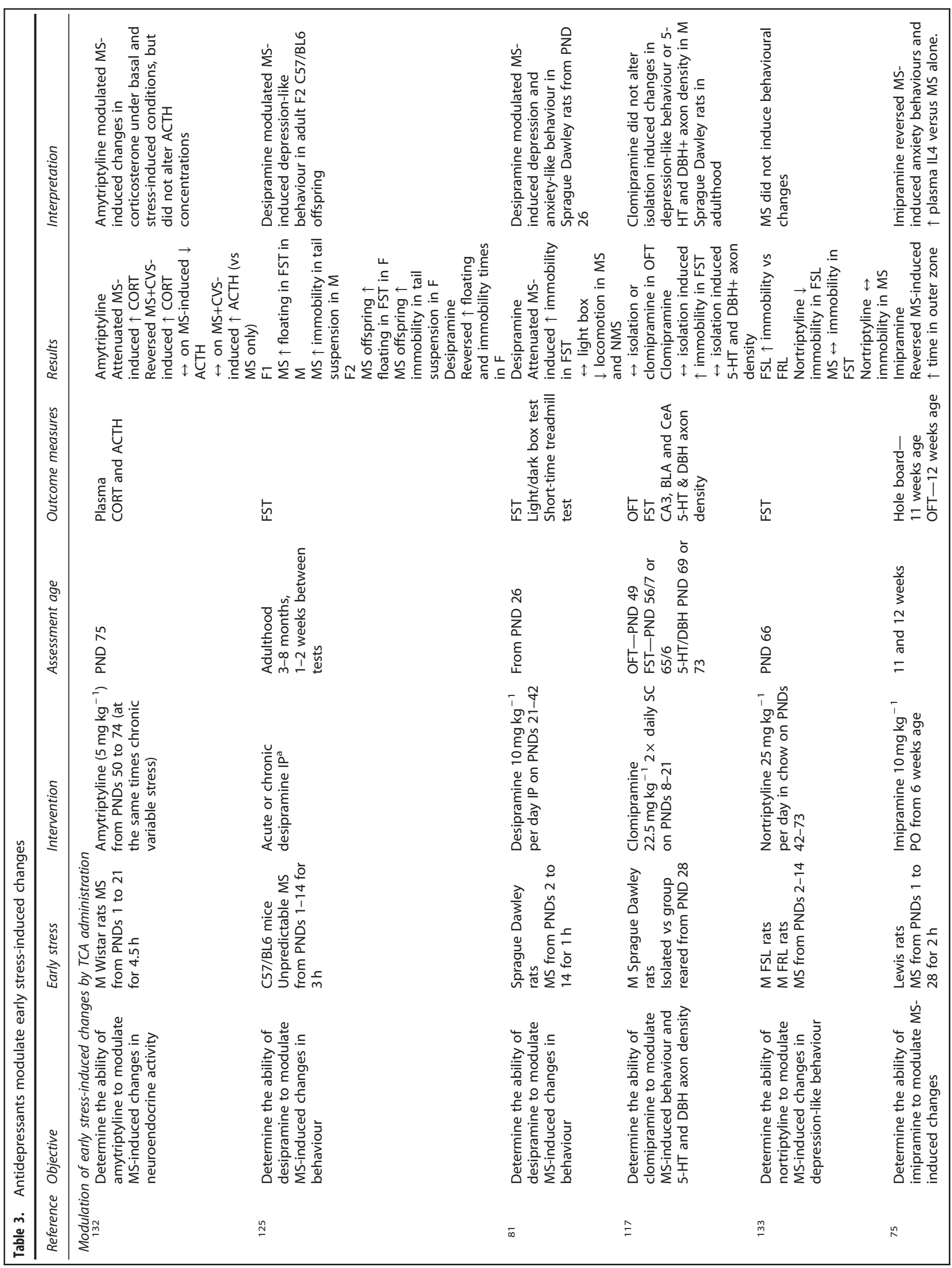




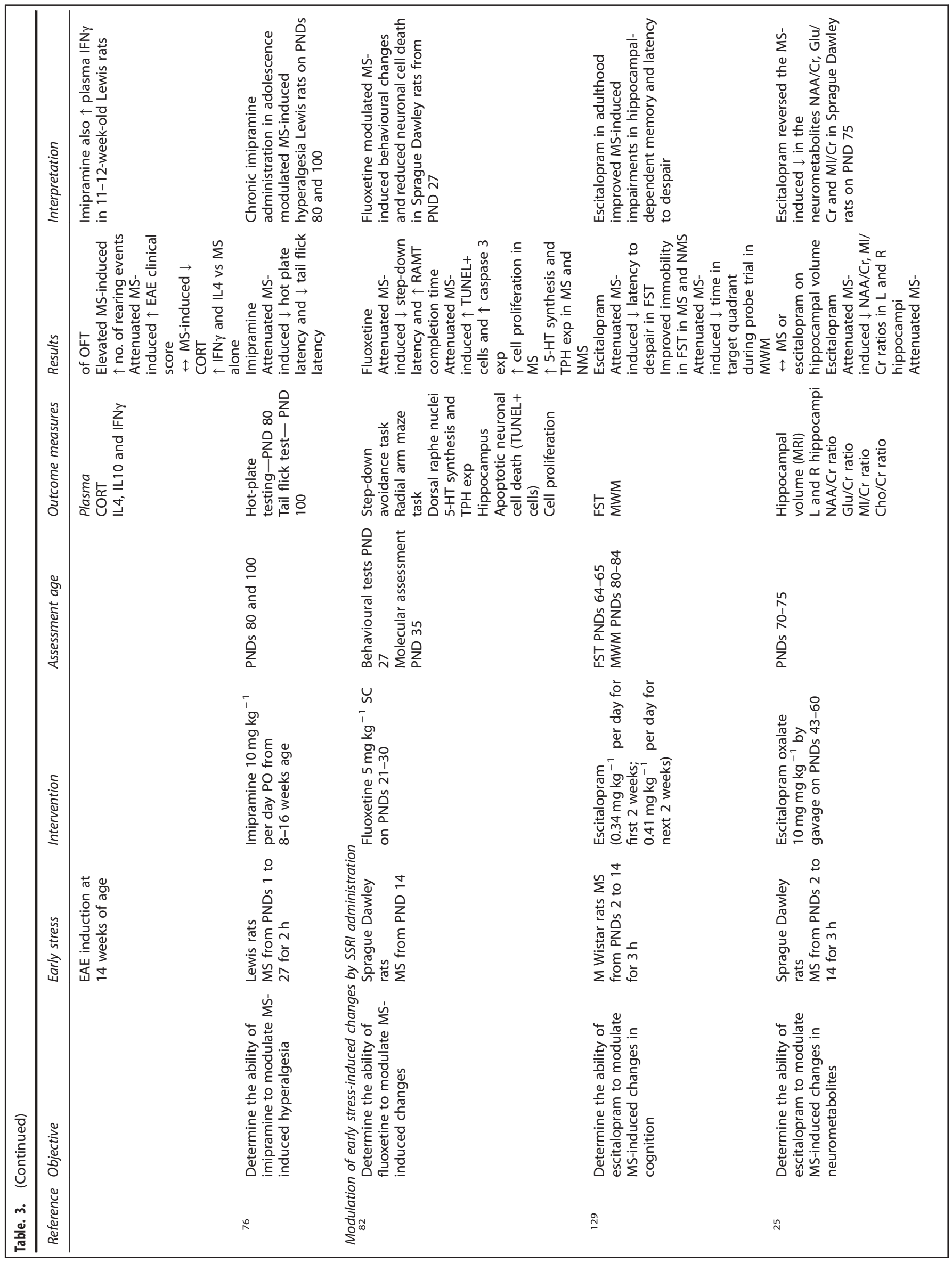




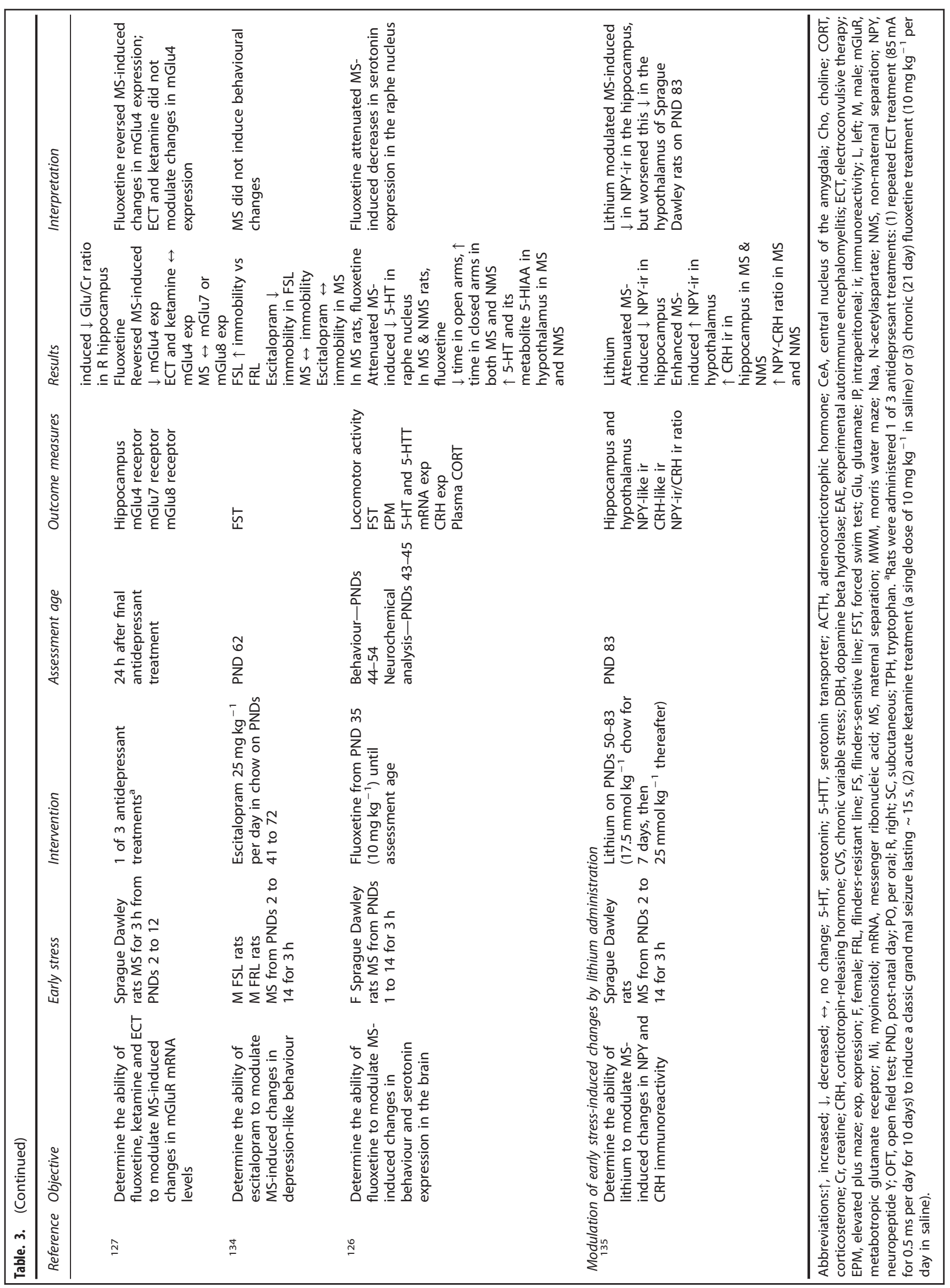


proliferation in the hippocampal dentate gyrus. Additionally, although not a modulatory effect, fluoxetine increased serotonin synthesis and tryptophan expression in the dorsal raphe nuclei in both separated and non-separated Sprague Dawley rats on PND $35 .{ }^{82}$ Others have reported similar modulation of the serotonergic system by fluoxetine following early stress. Female Sprague Dawley rats treated with fluoxetine from PND 35 displayed attenuation of maternal separation-induced reductions in serotonin expression in the raphe nucleus compared with control. ${ }^{126}$ Fluoxetine has also been shown to reverse separation-induced changes in metabotropic glutamate receptor 4 (mGluR4) expression in the hippocampus of Sprague Dawley rats in a study comparing the efficacy of fluoxetine with electroconvulsive therapy and ketamine. Interestingly, neither electroconvulsive therapy nor ketamine administration altered changes in mGluR4 expression in these maternally separated rats. ${ }^{127}$ As such, it may be hypothesised that fluoxetine exerts at least part of its therapeutic benefit by targeting group III mGlu receptors, thereby attenuating the reduction in mGluR4 receptors caused by early stress and preventing the decrease in negative feedback, which can ultimately lead to excessive glutamate release and hyperexcitability.

Escitalopram also appears to modulate cellular alterations induced by early stress. Decreased concentrations of the neurometabolites $\mathrm{N}$-acetylaspartate, choline and myoinositol, indicative of reduced neural density and functional integrity, were noted in the hippocampus of Sprague Dawley rats following maternal separation. ${ }^{128}$ These separation-induced changes in neurometabolite concentrations were attenuated significantly in escitalopram versus vehicle-treated rats in adulthood; ${ }^{128}$ separated escitalopram-treated rats displayed higher concentrations of these neurometabolites compared with separated rats that received vehicle. Consistent with this, others have reported that escitalopram reduced depression-like behaviour that occurred after maternal separation in Wistar rats. ${ }^{129}$ The mechanisms underlying the antidepressant effect of escitalopram are thought to be the result of either stimulation of neuronal remodelling in the hippocampus, ${ }^{130}$ or via modulation of the HPA axis. ${ }^{131}$ Furthermore, in the same experiment, improved hippocampaldependent memory in the probe trial of the Morris Water maze was demonstrated in escitalopram-treated rats, which is in line with the beneficial effects escitalopram exerts on separationinduced depression-like behaviours. ${ }^{129}$

Considered together, works examining the modulatory influence of TCAs and SSRIs indicate that modulation of monoaminergic signalling acts to attenuate or reverse alterations in behaviour induced by early stress, in addition to a number of cellular changes. The specific mechanisms underlying the way in which antidepressants achieve these effects remain to be fully characterised. It may be hypothesised that TCAs and SSRIs attenuate deficits in monoaminergic signalling caused by early stress, thereby partially restoring their function and the role they have in the regulation of stress-related behaviours. Modulation of the HPA axis ${ }^{131}$ and neuronal remodelling ${ }^{130}$ may also contribute to their effect on depression-like behaviours. Changes in memory capability following antidepressant administration may be the result of enhanced cell proliferation in the hippocampus. ${ }^{82}$ Clearly, the mechanisms underpinning these actions need to be further characterised in future models to ascertain at what level these drugs exert their influence (Table 3 ).

\section{EPIGENETIC-MODIFYING DRUGS MODULATE EARLY STRESS- INDUCED CHANGES}

The first studies assessing whether epigenetic changes induced by variations in the early environment were amenable to intervention centred on the use of methionine, a drug that enhances the methylation status of candidate genes. Generally, the methylation status of a candidate gene is inversely correlated with the level of gene expression; low levels of gene methylation have generally been associated with increased gene expression to date. ${ }^{136,137}$

Intracerebroventricular methionine administration from PNDs 97 to 103 in the offspring of high-care Long-Evans hooded dams has been shown to increase the methylation status of the nerve growth factor-inducible protein A (NGFI-A) consensus sequence of the exon $1_{7}$ GR promoter to the level of offspring of low-care dams. ${ }^{138}$ These results indicate that the influence of early environment on the epigenome are amenable to intervention in adulthood. A concomitant decrease in histone 3 lysine 9 (H3K9) in association with the exon $1_{7}$ GR promoter and decreased GR mRNA and protein expression in the hippocampus of high-care offspring was also demonstrated, once again to the level of lowcare offspring. ${ }^{138}$ Such findings suggest that the changes in the epigenome modified by methionine administration were functionally relevant. Specifically, methionine administration in highcare offspring was shown to enhance anxiety ${ }^{61}$ and depressionlike $^{62}$ behaviour to the level of low-care offspring. Such results illustrate that epigenetic alterations are associated with behavioural changes, potentially via their influence on the HPA axis and stress responsivity, and that it is possible to modulate changes in behaviour through the administration of epigenetic-modifying drugs such as methionine in adulthood. Although these results are of little translational benefit as they worsen behavioural changes induced by early stress, the findings demonstrate the susceptibility of the epigenome to pharmacologic manipulation in adulthood.

Initial studies on methionine lead to investigation into the ability of the DNA methylation inhibitor zebularine to modulate changes in brain-derived neurotrophic factor (BDNF) expression induced by early stress. ${ }^{12}$ Long Evans hooded rats exposed to abusive Long Evans mothers in childhood and treated with zebularine in adulthood (PNDs 83-89) displayed attenuation of stress-induced decreases in BDNF mRNA expression in the prefrontal cortex in adulthood compared with those that recieved vehicle. ${ }^{12}$ These findings are of interest as they illustrate that differences in DNA methylation, specifically gene hypermethylation, induced by early stress can be reversed in adulthood.

Post-translational histone modifications represent another epigenetic mechanism that appears to be modulated by the early environment, and level of care received by offspring. The level of histone acetylation correlates positively with the level of gene expression. ${ }^{139}$ Reduced histone acetylation therefore tends to result in decreased expression of a certain gene. Trichostatin A (TSA), a histone deacetylase inhibitor, reduces the rate of deacetylation of candidate genes, enhancing the level of histone acetylation and therefore gene expression. It has been shown that low levels of maternal care reduce histone acetylation in rat offspring, and result in decreased gene transcription and protein expression. ${ }^{138}$ In addition, TSA administration (from PNDs 90 to 97) in low-care offspring has been shown to enhance GR mRNA expression in the hippocampus to the level of high-care Long Evans hooded offspring. ${ }^{138}$ The authors extrapolated their findings in further work (utilising the same experimental design) demonstrating that TSA administration reduced anxiety-like behaviours of low-care offspring to the level of high-care offspring. ${ }^{62}$ Together, the results of this collection of works suggests that the adverse behavioural consequences associated with low levels of maternal care in early life are amenable to intervention in adulthood through histone deacetylase inhibitor administration.

Another histone deacetylase inhibitor, valproic acid, has been reported to attenuate decreases in acoustic startle in maternally separated female Sprague Dawley rats when administered during childhood. ${ }^{140}$ Interestingly however, valproic acid only modulated behaviour when administered in the early post-natal period (PNDs 2-9); administration from PNDs 28 to 36 did not influence behaviour, ${ }^{140}$ indicating that the ability of valproic acid to 


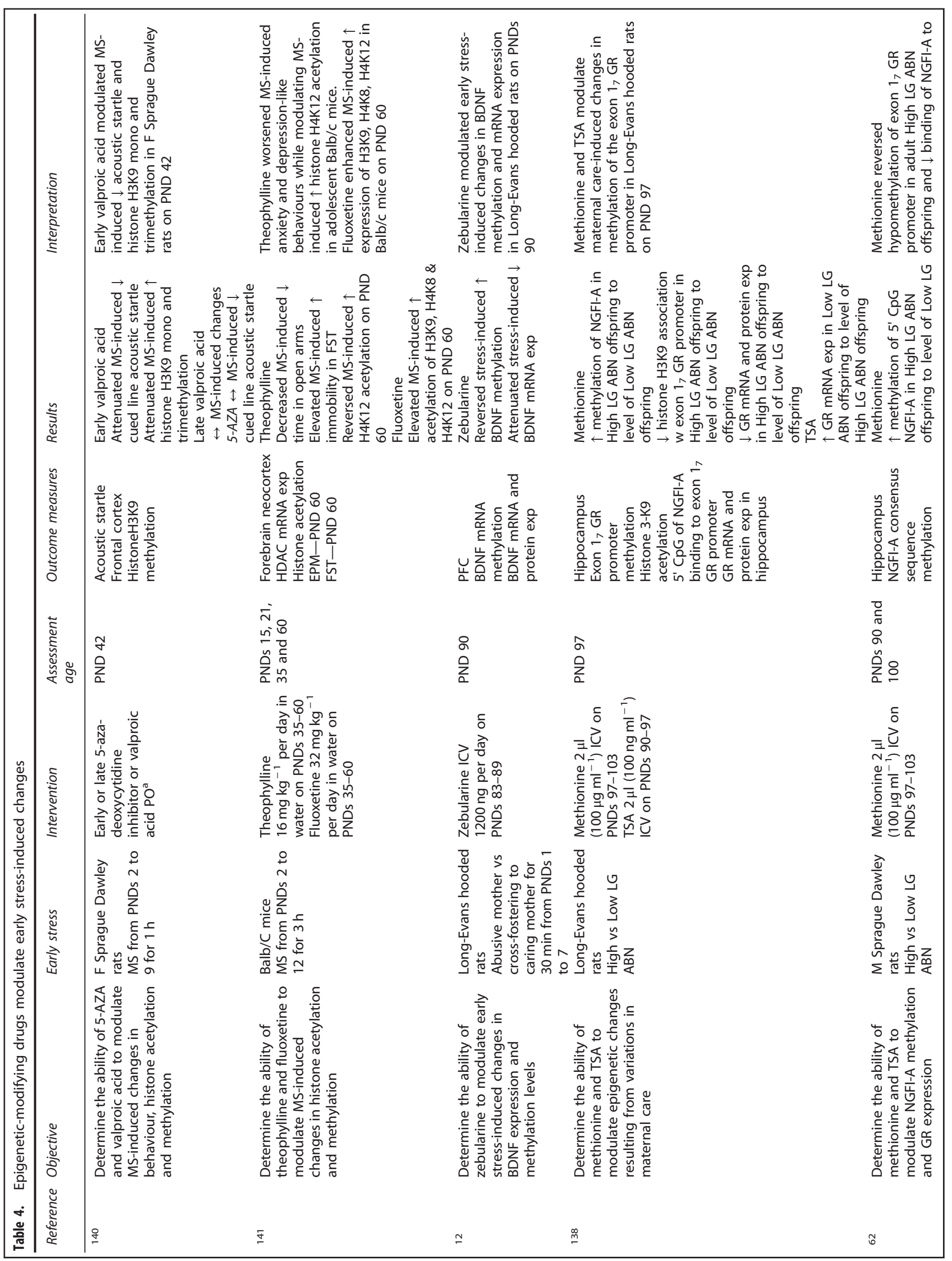




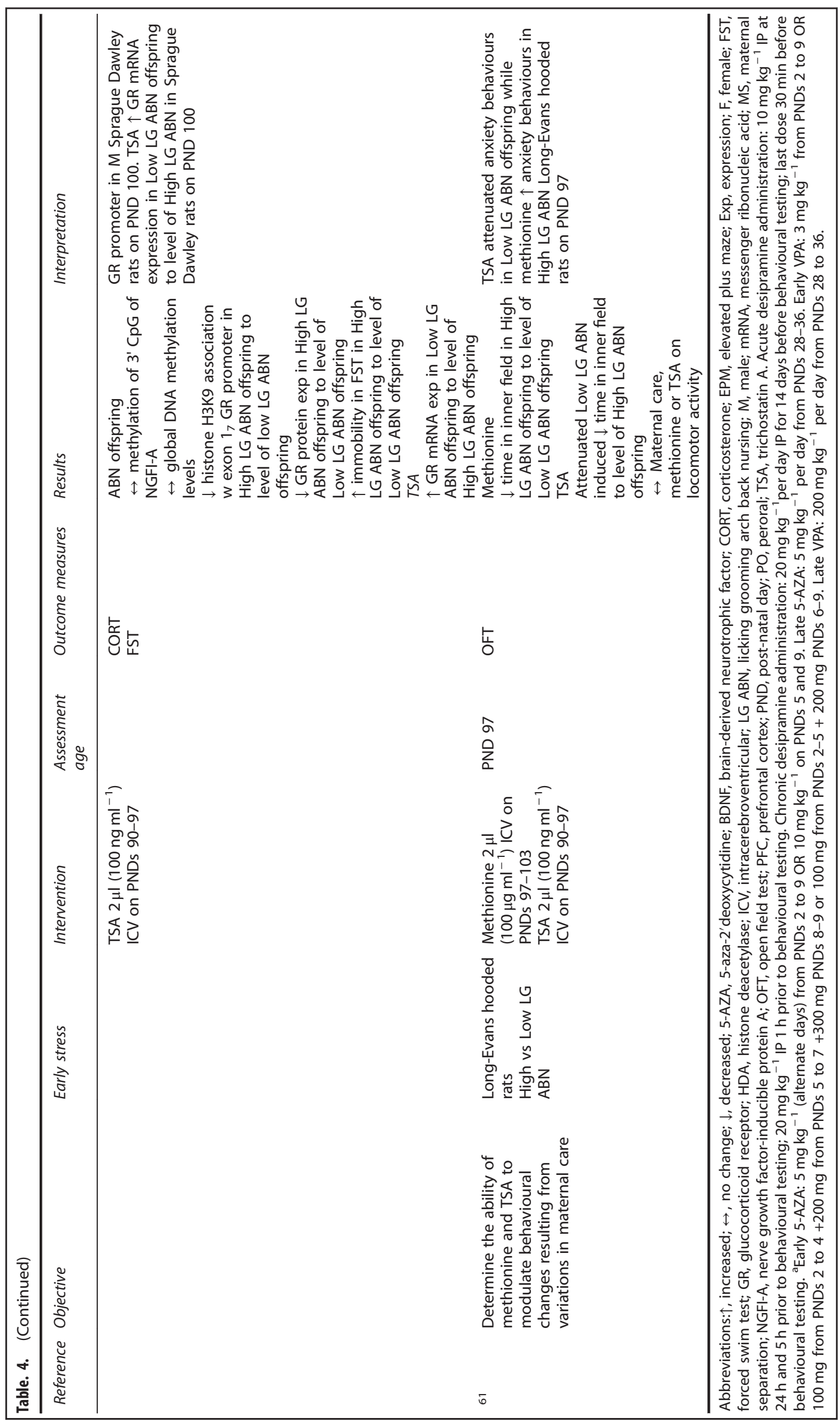


modulate changes in histone modifications may be timedependent. It is hypothesised that such time-dependent effects of valproic acid occur as decreased frontal cortical H3K9 monomethylation (due to maternal separation) is the cause of reduced acoustic startle responses, because it results in decreased expression of key genes involved in fear conditioning. As such, administration of valproic acid early in life reverses decreases in H3K9 monomethylation that occur due to separation, thereby preventing reduced expression of those genes involved in fear conditioning, thereby increasing acoustic startle responses compared with separated rats treated with vehicle.

Taken together, results from studies examining the modulatory influence of epigenetic-modifying drugs illustrate that changes in both DNA methylation and histone acetylation of candidate genes that occur in response to early environmental adversities are amenable to intervention. Of particular interest, administration of drugs in adulthood still appears to result in modulation of changes in the epigenome induced by early life stress. As such, earlier intervention with epigenetic-modifying drugs may be able to prevent the negative influence early stress exerts on the epigenome and protein expression of key candidate genes, including those involved in stress system regulation, and the influence such epigenetic changes exert on behaviour and disease susceptibility (Table 4).

\section{DISCUSSION}

It is widely accepted that individuals exposed to adversity in childhood tend to be relatively resistant to pharmacotherapy in clinical practice. ${ }^{142-144}$ Current interventions that aim to reduce the negative influence early stress exerts on later disease susceptibility are minimal at best. Findings from this review, although from animal studies only, suggest that some targeted interventions, particularly during early life, have the ability to attenuate or even reverse changes in neurobiology and behaviour that occur after adversity in childhood.

Findings from animal studies indicate that behavioural interventions such as SMG and $\mathrm{MH}$, exercise and pharmacotherapies such as epigenetic-modifying drugs are likely to be most efficacious in reducing the negative consequences of childhood adversity. Each of these interventions modulates specific early stress-induced changes in neurobiology on both cellular and behavioural levels. Modulation of the latter is likely to be of most importance from a clinical and translational perspective.

The relevance of interventions such as SMG and $\mathrm{MH}$, which potentially act though enhancing oxytocin signalling within the brain, is supported by reports of altered oxytocin levels following early stress. Exposure to adversity of early stress has been shown to alter OXTR expression and immunoreactivity in animal models of early stress, $33,145,146$ and also in children ${ }^{147}$ and adult humans. ${ }^{148,149}$ From a translational standpoint, this is of interest, as while it may be possible to implement behavioural interventions in children exposed to early adversity, behavioural therapies are less likely to be as well tolerated in adolescents and adults. As such, oxytocin administration may represent a novel way to enhance oxytocin signalling in these individuals, thereby attenuating the influence childhood stress exerts on neurobiology across the lifespan, and the predisposition to later disease. Additional research is required in animal models to ascertain the mechanisms underlying the influence of SMG and $\mathrm{MH}$, and to quantify their effects on the oxytocin system. It may then be possible to begin trialling these behavioural therapies in humans, to ascertain whether administration in childhood can reverse the sequelae of early stress, preventing the development of psychiatric disorders, and if intervention later in life can influence the extent of treatment resistance commonly seen in those with a history of childhood adversity and established psychiatric conditions.
From a translational perspective, the minimal side effect profile of exercise makes it a promising therapeutic option for both the prevention and treatment of psychiatric conditions. It can be adjusted on a patient-by-patient basis according to comorbidities and functional status. ${ }^{150-152}$ Clinical models point towards improved relapse prevention in patients treated with exercise compared with those treated with some pharmacotherapies, ${ }^{153}$ and synergism between some drug therapies and exercise exists. ${ }^{154}$ Findings from animal models also indicate that exercise can attenuate some of the negative neurobiological changes that result from early adversity. Exercise may be of benefit in the clinical setting, potentially acting as a preventative measure reducing the sequelae of childhood adversity and decreasing the predisposition to psychiatric disease. In those with current psychiatric conditions and a history of childhood adversity, the antidepressant- and neuroplasticity-enhancing effects of exercise may enable it to attenuate the extent to which early adversity influences neurobiology, thereby potentially reducing treatment resistance. Further work is required to delineate how to translate exercise therapy into human studies and then clinical practice. The influence the type, duration and frequency of exercise exerts on its modulatory ability requires investigation to ensure its benefits are obtained. The age at which exercise therapy should be introduced in order for it to act as a preventative measure following childhood adversity must also be established.

The ability of epigenetic-modifying drugs, such as DNA methylation inhibitors and histone deacetylase inhibitors, makes them a promising option to alter neurobiological changes induced by early stress across the lifespan. Additionally, their effects are more wide-ranging than those of other pharmacotherapies, in that they influence not only epigenetic changes induced by early stress but also the resultant alterations in neuroendocrine axis regulation and behaviour. Additionally, they appear to be able to effectively modulate early stress-induced changes in adulthood, often to a greater degree than other pharmacotherapies such as antidepressants, which can be less effective later in life. Given the positive findings from animal models of early stress, clinical studies are required to ascertain the efficacy and safety of epigenetic-modifying drugs in humans. It may be that if administered in childhood, DNA methylation inhibitors are able to reverse the hypersensitive, exaggerated stress response that frequently persists following childhood adversity, and the way in which it enhances the predisposition to psychiatric disorders development. As animal studies suggest that epigenetic changes can be modified in adulthood, intervention with these drugs later in life may act to attenuate the extent to which childhood stress influences neurobiology and the predisposition to disease.

\section{CONCLUSION}

Findings from this review suggest that the neurobiological sequelae of early stress can be attenuated or even reversed in animal models. Considerable effort is required before both behavioural and pharmacological therapies aimed at reducing the vulnerability to psychiatric disorders in those exposed to stress in childhood can be implemented in clinical practice. However, there are substantial gains to be had should the neurobiological sequelae of early adversity be amenable to intervention in humans. It may be possible to reduce or even eliminate characteristics of the vulnerable phenotype, thereby decreasing the incidence of psychiatric disorders in individuals with a history of childhood adversity.

\section{CONFLICT OF INTEREST}

The authors declare no conflict of interest. 


\section{ACKNOWLEDGMENTS}

The presented work is supported by the National Health and Medical Research Council Australia (APP1003788 to BTB) and the Royal Australian and New Zealand College of Psychiatrists Young Investigator Award (RANZCP to ELH). The funders had no role in study design, data collection and analysis, decision to publish or preparation of the manuscript.

\section{DISCLAIMER}

The funders had no role in study design, data collection and analysis, decision to publish or preparation of the manuscript.

\section{REFERENCES}

1 Scher CD, Forde DR, McQuaid JR, Stein MB. Prevalence and demographic correlates of childhood maltreatment in an adult community sample. Child Abuse Negl 2004; 28: 167-180.

2 Ehlert U, Gaab J, Heinrichs M. Psychoneuroendocrinological contributions to the etiology of depression, posttraumatic stress disorder, and stress-related bodily disorders: the role of the hypothalamus-pituitary-adrenal axis. Biol Psychol 2001; 57: 141-152.

3 Gilman SE, Kawachi I, Fitzmaurice GM, Buka SL. Family disruption in childhood and risk of adult depression. Am J Psychiatry 2003; 160: 939-946.

4 Jaffee SR, Moffitt TE, Caspi A, Fombonne E, Poulton R, Martin J. Differences in early childhood risk factors for juvenile-onset and adult-onset depression. Arch Gen Psychiatry 2002; 59: 215-222.

5 Takeuchi H, Hiroe T, Kanai T, Morinobu S, Kitamura T, Takahashi K et al. Childhood parental separation experiences and depressive symptomatology in acute major depression. Psychiatry Clin Neurosci 2003; 57: 215-219.

6 Heim C, Newport DJ, Miller AH, Nemeroff CB. Long-term neuroendocrine effects of childhood maltreatment. JAMA 2000; 284: 2321.

7 Wegman HL, Stetler C. A meta-analytic review of the effects of childhood abuse on medical outcomes in adulthood. Psychosom Med 2009; 71: 805.

8 Thomas C, Hypponen E, Power C. Obesity and type 2 diabetes risk in midadult life: the role of childhood adversity. Pediatrics 2008; 121: e1240-e1249.

9 Felitti VJ, Anda RF, Nordenberg D, Williamson DF, Spitz AM, Edwards et al. Relationship of childhood abuse and household dysfunction to many of the leading causes of death in adults. The Adverse Childhood Experiences (ACE) Study. Am J Prev Med 1998; 14: 245-258.

10 Murray J Lopez A. Summary-The Global Burden of Disease. Harvard School of Public Health: Boston, MA, USA, 1996).

11 Zimmerberg B, Shartrand AM. Temperature-dependent effects of maternal separation on growth, activity, and amphetamine sensitivity in the rat. Dev Psychobiol 1992; 25: 213-226.

12 Roth TL, Lubin FD, Funk A, Sweatt JD. Lasting epigenetic influence of early-life adversity on the BDNF gene. Biol Psychiatry 2009; 65: 760-769.

13 Champagne FA, Weaver IC, Diorio J, Sharma S, Meaney MJ. Natural variations in maternal care are associated with estrogen receptor alpha expression and estrogen sensitivity in the medial preoptic area. Endocrinology 2003; 144: 4720-4724.

14 Rice CJ, Sandman CA, Lenjavi MR, Baram TZ. A novel mouse model for acute and long-lasting consequences of early life stress. Endocrinology 2008; 149: 4892-4900.

15 Wang X-D, Deussing JM, Baram TZ, Stewart MG, Miller MB, Schmidt MV et al. Forebrain CRF1 modulates early-life stress-programmed cognitive deficits. J Neurosci 2011; 31: 13625-13634.

16 Lynch MA. Long-term potentiation and memory. Physiological Rev 2004; 84: 87-136.

17 Chen Y, Dube CM, Rice CJ, Baram TZ. Rapid loss of dendritic spines after stress involves derangement of spine dynamics by corticotropin-releasing hormone. $J$ Neurosci 2008; 28: 2903-2911.

18 Kaplow JB, Dodge KA, Amaya-Jackson L, Saxe GN. Pathways to PTSD, part II: sexually abused children. Am J Psychiatry 2005; 162: 1305-1310.

19 Marais L, van Rensburg SJ, van Zyl JM, Stein DJ, Daniels WMU. Maternal separation of rat pups increases the risk of developing depressive-like behavior after subsequent chronic stress by altering corticosterone and neurotrophin levels in the hippocampus. Neurosci Res 2008; 61: 106-112.

20 Kember RL, Dempster EL, Lee THA, Schalkwyk LC, Mill J, Fernandes C. Maternal separation is associated with strain-specific responses to stress and epigenetic alterations to Nr3c1, Avp, and Nr4a1 in mouse. Brain Behav 2012; 2: 455-467.

21 Lehmann J. Comparison of maternal separation and early handling in terms of their neurobehavioral effects in aged rats. Neurobiol Aging 2002; 23: 457-466.
22 Own LS, Iqbal R, Patel PD. Maternal separation alters serotonergic and HPA axis gene expression independent of separation duration in c57bl/6 mice. Brain Res 2013; 1515: 29-38.

23 Aisa B, Tordera R, Lasheras B, Del Rio J, Ramirez MJ. Cognitive impairment associated to HPA axis hyperactivity after maternal separation in rats. Psychoneuroendocrinology 2007; 32: 256-266.

24 Oomen CA, Soeters H, Audureau N, Vermunt L, van Hasselt FN, Manders EMM et al. Early maternal deprivation affects dentate gyrus structure and emotional learning in adult female rats. Psychopharmacology 2011; 214: 249-260.

25 Hui JJ, Zhang ZJ, Liu SS, Xi GJ, Zhang XR, Teng GJ et al. Hippocampal neurochemistry is involved in the behavioural effects of neonatal maternal separation and their reversal by post-weaning environmental enrichment: a magnetic resonance study. Behav Brain Res 2011; 217: 122-127.

26 Macri S, Mason GJ, Wurbel H. Dissociation in the effects of neonatal maternal separations on maternal care and the offspring's HPA and fear responses in rats. Eur J Neurosci 2004; 20: 1017-1024.

27 Millstein RA, Holmes A. Effects of repeated maternal separation on anxiety- and depression-related phenotypes in different mouse strains. Neurosci Biobehav Rev 2007; 31: 3-17.

28 Parfitt DB, Levin JK, Saltstein KP, Klayman AS, Greer LM, Helmreich DL. Differential early rearing environments can accentuate or attenuate the responses to stress in male C57BL/6 mice. Brain Res 2004; 1016: 111-118.

29 Savignac HM, Dinan TG, Cryan JF. Resistance to early-life stress in mice: effects of genetic background and stress duration. Front Behav Neurosci 2011; 5: 13.

30 Teicher MH, Andersen SL, Polcari A, Anderson CM, Navalta CP. Developmental neurobiology of childhood stress and trauma. Psychiatr Clin North Am 2002; 25: 397-426.

31 Jankovic BD, Isakovic K, Micic M, Knezevic Z. The embryonic lympho-neuroendocrine relationship. Clin Immunol Immunopathol 1981; 18: 108-120.

32 Miller GE, Chen E, Parker KJ. Psychological stress in childhood and susceptibility to the chronic diseases of aging: moving toward a model of behavioral and biological mechanisms. Psychol Bull 2011; 137: 959-997.

33 Veenema AH, Bredewold R, Neumann ID. Opposite effects of maternal separation on intermale and maternal aggression in C57BL/6 mice: Link to hypothalamic vasopressin and oxytocin immunoreactivity. Psychoneuroendocrinology 2007; 32: 437-450.

34 Aisa B, Tordera R, Lasheras B, Del Rio J, Ramirez MJ. Effects of maternal separation on hypothalamic-pituitary-adrenal responses, cognition and vulnerability to stress in adult female rats. Neuroscience 2008; 154: 1218-1226.

35 Lee J-H, Kim B-T, Kim HJ, Kim JG, Ryu V, Kang D-W et al. Depressive behaviors and decreased expression of serotonin reuptake transporter in rats that experienced neonatal maternal separation. Neurosci Res 2007; 58: 32-39.

36 MacQueen GM, Ramakrishnan K, Ratnasingan R, Chen B, Young LT. Desipramine treatment reduces the long-term behavioural and neurochemical sequelae of early-life maternal separation. Neuropsychopharmacology 2003; 6: 391-396.

37 Matthews K, Robbins TW. Early experience as a determinant of adult behavioural responses to reward: the effects of repeated maternal separation in the rat. Neurosci Biobehav Rev 2003; 27: 45-55.

38 Aisa B, Elizalde N, Tordera R, Lasheras B, Del Rio J, Ramirez MJ. Effects of neonatal stress on markers of synaptic plasticity in the hippocampus: implications for spatial memory. Hippocampus 2009; 19: 1222-1231.

39 Fabricius K, Wortwein G, Pakkenberg B. The impact of maternal separation on adult mouse behaviour and on the total neuron number in the mouse hippocampus. Brain Struct Funct 2008; 212: 403-416.

40 Ivy AS, Rex CS, Chen Y, Dube C, Maras PM, Grigoriadis DE et al. Hippocampal dysfunction and cognitive impairments provoked by chronic early-life stress involve excessive activation of $\mathrm{CRH}$ receptors. Neuroscience 2010; 30: 13005-13015.

41 Kalinichev M, Easterling KW, Plotsky PM, Holtzman SG. Long-lasting changes in stress-induced corticosterone response and anxiety-like behaviors as a consequence of neonatal maternal separation in Long-Evans rats. Pharmacol Biochem Behav 2002; 73: 131-140.

42 Meaney MJ. Maternal care, gene expression, and the transmission of individual differences in stress reactivity across generations. Annu Rev Neurosci 2001; 24: 1161-1192.

43 Lippmann M, Bress A, Nemeroff CB, Plotsky PM, Monteggia LM. Long-term behavioural and molecular alterations associated with maternal separation in rats. Eur J Neurosci 2007; 25: 3091-3098.

44 Coe CL, Erickson CM. Stress decreases lymphocyte cytolytic activity in the young monkey even after blockade of steroid and opiate hormone receptors. Dev Psychobiol 1996; 30: 1-10.

45 Laudenslager ML, Held PE, Boccia ML, Reite ML, Cohen JJ. Behavioral and immunological consequences of brief mother-infant separation: a species comparison. Dev Psychobiol 1990; 23: 247-264. 
46 Laudenslager ML, Reite M, Harbeck RJ. Suppressed immune response in infant monkeys associated with maternal separation. Behavi Neural Biol 1982; 36: 40-48.

47 Stiller AL, Drugan RC, Hazi A, Kent SP. Stress resilience and vulnerability: the association with rearing conditions, endocrine function, immunology, and anxious behavior. Psychoneuroendocrinology 2011; 36: 1383-1395.

48 Kanitz E, Tuchscherer M, Puppe B, Tuchscherer A, Stabenow B. Consequences of repeated early isolation in domestic piglets (Sus scrofa) on their behavioural, neuroendocrine, and immunological responses. Brain Behav Immun 2004; 18 : 35-45.

49 Llorente R, Arranz L, Marco EM, Moreno E, Puerto M, Guaza C et al. Early maternal deprivation and neonatal single administration with a cannabinoid agonist induce long-term sex-dependent psychoimmunoendocrine effects in adolescent rats. Psychoneuroendocrinology 2007; 32: 636-650.

50 Tuchscherer M, Kanitz E, Puppe B, Tuchscherer A, Viergutz T. Changes in endocrine and immune responses of neonatal pigs exposed to a psychosocial stressor. Res Vet Sci 2009; 87: 380-388.

51 Tuchscherer M, Kanitz E, Puppe B, Tuchscherer A, Stabenow B. Effects of postnatal social isolation on hormonal and immune responses of pigs to an acute endotoxin challenge. Physiol Behav 2004; 82: 503-511.

52 Avitsur R, Sheridan JF. Neonatal stress modulates sickness behavior. Brain Behav Immun 2009; 23: 977-985.

53 O'Mahony SM, Marchesi JR, Scully P, Codling C, Ceolho A-M, Quigley EMM et al. Early life stress alters behavior, immunity, and microbiota in rats: implications for irritable bowel syndrome and psychiatric illnesses. Biol Psychiatry 2009; 65 263-267.

54 Teunis MAT, Heijnen CJ, Sluyter F, Bakker JM, Van Dam A-MMW, Hof M et al. Maternal deprivation of rat pups increases clinical symptoms of experimenta autoimmune encephalomyelitis at adult age. J Neuroimmunol 2002; 133: 30-38.

55 Vig R, Gordon JR, Thebaud B, Befus AD, Vliagoftis H. The effect of early-life stress on airway inflammation in adult mice. Neuroimmunomodulation 2010; 17: 229-239.

56 Ohta K-i Miki T, Warita K, Suzuki S, Kusaka T, Yakura T et al. Prolonged maternal separation disturbs the serotonergic system during early brain development. Int J Dev Neurosci 2014; 33: 15-21.

57 Li M, Xue X, Shao S, Shao F, Wang W. Cognitive, emotional and neurochemical effects of repeated maternal separation in adolescent rats. Brain Res 2013; 1518: 82-90.

58 Jahng JW, Ryu V, Yoo SB, Noh SJ, Kim JY, Lee JH. Mesolimbic dopaminergic activity responding to acute stress is blunted in adolescent rats that experienced neonatal maternal separation. Neuroscience 2010; 171: 144-152.

59 Franklin TB, Linder N, Russig H, Thony B, Mansuy IM. Influence of early stress on social abilities and serotonergic functions across generations in mice. PloS One 2011; 6: e21842.

60 Leussis MP, Freund N, Brenhouse HC, Thompson BS, Andersen SL. Depressivelike behavior in adolescents after maternal separation: sex differences, controllability, and GABA. Dev Neurosci 2012; 34: 210-217.

61 Weaver IC, Meaney MJ, Szyf M. Maternal care effects on the hippocampal transcriptome and anxiety-mediated behaviors in the offspring that are reversible in adulthood. Proc Natl Acad Sci USA 2006; 103: 3480-3485.

62 Weaver IC, Champagne FA, Brown SE, Dymov S, Sharma S, Meaney MJ et al. Reversal of maternal programming of stress responses in adult offspring through methyl supplementation: altering epigenetic marking later in life. J Neurosc 2005; 25: 11045-11054.

63 Champagne FA, Weaver ICG, Diorio J, Dymov S, Szyf M, Meaney MJ. Maternal care associated with methylation of the estrogen receptor-alpha1b promoter and estrogen receptor-alpha expression in the medial preoptic area of female offspring. Endocrinology 2006; 147: 2909-2915.

64 Fahrbach SE, Morrell Jl, Pfaff DW. Possible role for endogenous oxytocin in estrogen-facilitated maternal behavior in rats. Neuroendocrinology 1985; 40: 526-532.

65 Francis DD, Champagne FC, Meaney MJ. Variations in maternal behaviour are associated with differences in oxytocin receptor levels in the rat. $J$ Neuroendocrinol 2000; 12: 1145-1148.

66 Numan M, Sheehan TP. Neuroanatomical circuitry for mammalian maternal behavior. Ann NY Acad Sci 1997; 807: 101-125.

67 Neumann ID, Johnstone HA, Hatzinger M, Liebsch G, Shipston M, Russell JA et al. Attenuated neuroendocrine responses to emotional and physical stressors in pregnant rats involve adenohypophysial changes. J Physiol 1998; 508: 289-300.

68 Kramer KM, Cushing BS, Carter CS. Developmental effects of oxytocin on stress response: single versus repeated exposure. Physiol Behav 2003; 79: 775-782.

69 Cohen H, Kaplan Z, Kozlovsky N, Gidron Y, Matar MA, Zohar J. Hippocampal microinfusion of oxytocin attenuates the behavioural response to stress by means of dynamic interplay with the glucocorticoid-catecholamine responses. $J$ Neuroendocrinol 2010; 22: 889-904.
70 Neumann ID, Wigger A, Torner L, Holsboer F, Landgraf R. Brain oxytocin inhibits basal and stress-induced activity of the hypothalamo-pituitary-adrenal axis in male and female rats: partial action within the paraventricular nucleus. $J \mathrm{Neu}$ roendocrinol 2000; 12: 235-243.

71 Windle RJ, Shanks N, Lightman SL, Ingram CD. Central oxytocin administration reduces stress-induced corticosterone release and anxiety behavior in rats. Endocrinology 1997; 138: 2829-2834.

72 Uvnas-Moberg K, Bruzelius G, Alster P, Bileviciute I, Lundeberg T. Oxytocin increases and a specific oxytocin antagonist decreases pain threshold in male rats. Acta Physiol Scand 1992; 144: 487-488.

73 Petersson M, Alster P, Lundeberg T, Uvnas-Moberg K. Oxytocin increases nociceptive thresholds in a long-term perspective in female and male rats. Neurosci Lett 1996; 212: 87-90.

74 Lenz KM, Sengelaub DR. Maternal care effects on the development of a sexually dimorphic motor system: the role of spinal oxytocin. Horm Behav 2010; 58 : 575-581.

75 Stephan M, Straub RH, Breivik T, Pabst R, von Hoersten S. Postnatal maternal deprivation aggravates experimental autoimmune encephalomyelitis in adult Lewis rats- reversal by chronic imipramine treatment. Int J Dev Neurosci 2002; 20: 125-132.

76 Stephan M, Helfritz F, Pabst R, von Horsten S. Postnatally induced differences in adult pain sensitivity depend on genetics, gender and specific experiences: reversal of maternal deprivation effects by additional postnatal tactile stimulation or chronic imipramine treatment. Behav Brain Res 2002; 133: 149-158.

77 Babygirija R, Yoshimoto S, Gribovskaja-Rupp I, Bulbul M, Ludwig K, Takahashi T. Social interaction attenuates stress responses following chronic stress in maternally separated rats. Brain Res 2012; 1469: 54-62.

78 Eyre H, Papps E, Baune BT. Treating depression and depression-like behavior with physical activity: an immune perspective. Front Psychiatry 2013; 4: 3.

79 Colcombe S, Kramer AF. Fitness effects on the cognitive function of older adults: a meta-analytic study. Psychol Sci 2003; 14: 125-130.

80 Voelcker-Rehage C, Niemann C. Structural and functional brain changes related to different types of physical activity across the life span. Neurosci Biobehav Rev 2013; 37: 2268-2295.

81 Huang TY, Lin CH. A comparison between chronic exercise training and desipramine as treatments for the depression-like behavior of early-life maternal deprivation rats. Neurosci Lett 2010; 480: 201-205.

82 Baek S-S, Jun T-W, Kim K-J, Shin M-S, Kang S-Y, Kim C-J. Effects of postnatal treadmill exercise on apoptotic neuronal cell death and cell proliferation of maternal-separated rat pups. Brain Dev 2012; 34: 45-56.

83 Crespi F, Wright IK, Mobius C. Isolation rearing of rats alters release of 5 hydroxytryptamine and dopamine in the frontal cortex: an in vivo electrochemical study. Exp Brain Res 1992; 88: 495-501.

84 Fulford AJ, Marsden CA. Conditioned release of 5-hydroxytryptamine in vivo in the nucleus accumbens following isolation-rearing in the rat. Neuroscience 1998; 83: 481-487.

85 Blomstrand E. Amino acids and central fatigue. Amino Acids 2001; 20: 25-34.

86 Daniels WMU, Marais L, Stein DJ, Russell V. Exercise normalizes altered expression of proteins in the ventral hippocampus of rats subjected to maternal separation. Exp Physiol 2012; 97: 239-247.

87 Hescham S, Grace L, Kellaway LA, Bugarith K, Russell VA. Effect of exercise on synaptophysin and calcium/calmodulin-dependent protein kinase levels in prefrontal cortex and hippocampus of a rat model of developmental stress. Metab Brain Dis 2009; 24: 701-709.

88 Baroncelli L, Braschi C, Spolidoro M, Begenisic T, Sale A, Maffei L. Nurturing brain plasticity: impact of environmental enrichment. Cell Death Differ 2010; 17: 1092-1103.

89 Petrosini L, De Bartolo P, Foti F, Gelfo F, Cutuli D, Leggio MG et al. On whether the environmental enrichment may provide cognitive and brain reserves. Brain Res Rev 2009; 61: 221-239.

90 Fox C, Merali Z, Harrison C. Therapeutic and protective effect of environmental enrichment against psychogenic and neurogenic stress. Behav Brain Res 2006; 175: $1-8$.

91 Hutchinson KM, McLaughlin KJ, Wright RL, Bryce Ortiz J, Anouti DP, Mika A et al. Environmental enrichment protects against the effects of chronic stress on cognitive and morphological measures of hippocampal integrity. Neurobio Learn Mem 2012; 97: 250-260.

92 Segovia G, Del Arco A, de Blas M, Garrido P, Mora F. Effects of an enriched environment on the release of dopamine in the prefrontal cortex produced by stress and on working memory during aging in the awake rat. Behav Brain Res 2008; 187: 304-311.

93 Vivinetto AL, Suarez MM, Rivarola MA. Neurobiological effects of neonatal maternal separation and post-weaning environmental enrichment. Behav Brain Res 2013; 240: 110-118. 
94 Grace L, Hescham S, Kellaway LA, Bugarith K, Russell VA. Effect of exercise on learning and memory in a rat model of developmental stress. Metab Brain Dis 2009; 24: 643-657.

95 Dimatelis JJ, Stein DJ, Russell VA. Behavioral changes after maternal separation are reversed by chronic constant light treatment. Brain Res 2012; 1480: 61-71.

96 Fride E. Endocannabinoids in the central nervous system: from neuronal networks to behavior. Curr Drug Targets CNS Neurol Disord 2005; 4: 633-642.

97 Fride $\mathrm{E}$. The endocannabinoid-CB receptor system: Importance for development and in pediatric disease. Neuro Endocrinol Lett 2004; 25: 24.

98 Berghuis P, Canty A, Irving AJ, Katona In, Yanagawa Y, Rakic P et al. Hardwiring the brain: endocannabinoids shape neuronal connectivity. Science 2007; 316: 1212-1216.

99 Harkany T, Guzman M, Galve-Roperh I, Berghuis P, Devi LA, Mackie K. The emerging functions of endocannabinoid signaling during CNS development. Trends Pharmacol Sci 2007; 28: 83-92.

100 Viveros Ma-P, Marco E-Ma, Llorente R, Lopez-Gallardo M. Endocannabinoid system and synaptic plasticity: implications for emotional responses. Neural Plast 2007; 52908-52912.

101 Martinez-Orgado J, Fernandez-Frutos B, Gonzalez R, Romero E, Urigüen L, Romero J et al. Neuroprotection by the cannabinoid agonist WIN-55212 in an in vivo newborn rat model of acute severe asphyxia. Brain Res Mol Brain Res 2003; 114: 132-139.

102 Marco EM, Adriani W, Canese R, Podo F, Viveros MP, Laviola G. Enhancement of endocannabinoid signalling during adolescence: modulation of impulsivity and long-term consequences on metabolic brain parameters in early maternally deprived rats. Pharmacol Biochem Behav 2007; 86: 334-345.

103 Llorente R, Llorente-Berzal A, Petrosino S, Marco EM, Guaza C, Prada C et al. Gender-dependent cellular and biochemical effects of maternal deprivation on the hippocampus of neonatal rats: a possible role for the endocannabinoid system. Dev Neurobiol 2008; 68: 1334-1347.

104 Jiang W, Zhang Y, Xiao L, Van Cleemput J, Ji S-P, Bai G et al. Cannabinoids promote embryonic and adult hippocampus neurogenesis and produce anxiolytic- and antidepressant-like effects. J Clin Invest 2005; 115: 3104-3116.

105 Lopez-Gallardo M, Llorente R, Llorente-Berzal A, Marco EM, Prada C, Di Marzo et al. Neuronal and glial alterations in the cerebellar cortex of maternally deprived rats: gender differences and modulatory effects of two inhibitors of endocannabinoid inactivation. Dev Neurobiol 2008; 68: 1429-1440.

106 Lisman JE, Coyle JT, Green RW, Javitt DC, Benes FM, Heckers S et al. Circuit-based framework for understanding neurotransmitter and risk gene interactions in schizophrenia. Trends Neurosci 2008; 31: 234-242.

107 Sibille E, Morris HM, Kota RS, Lewis DA. GABA-related transcripts in the dorsolateral prefrontal cortex in mood disorders. Int J Neuropsychopharmacol 2011; 14: 721-734.

108 Lewis D, Hashimoto T, Volk D. Cortical inhibitory neurons and schizophrenia. Nat Rev Neurosci 2005; 6: 312-324.

109 Belzung C, El Hage W, Moindrot N, Griebel G. Behavioral and neurochemical changes following predatory stress in mice. Neuropharmacology 2001; 41: 400-408.

110 Brenhouse HC, Andersen SL. Nonsteroidal anti-inflammatory treatment prevents delayed effects of early life stress in rats. Biol Psychiatry 2011; 70: 434-440.

111 Heather CS-B, Theodora K, Karen F, Anthony SB, Jeffrey HK, Raymond TB et al. Inhibitors of cyclooxygenase-2, but not cyclooxygenase-1 provide structural and functional protection against quinolinic acid-induced neurodegeneration. $J$ Pharmacol Exp Ther 2003; 306: 218-228.

112 Madrigal JLM, Moro MaA, Lizasoain I, Lorenzo P, Fernandez AP, Rodrigo J et al. Induction of cyclooxygenase-2 accounts for restraint stress-induced oxidative status in rat brain. Neuropsychopharmacology 2003; 28: 1579-1588.

113 Wu Chen R, Zhang Y, Rose ME, Graham SH. Cyclooxygenase-2 activity contributes to neuronal expression of cyclin D1 after anoxia/ischemia in vitro and in vivo. Brain Res Mol Brain Res 2004; 132: 31-37.

114 Ferri CC, Ferguson AV. Prostaglandin E2 mediates cellular effects of interleukin1 beta on parvocellular neurones in the paraventricular nucleus of the hypothalamus. J Neuroendocrinol 2005; 17: 498-508.

115 Takadera T, Ohyashiki T. Prostaglandin E2 deteriorates N-methyl-D-aspartate receptor-mediated cytotoxicity possibly by activating EP2 receptors in cultured cortical neurons. Life Sci 2006; 78: 1878-1883.

116 Takadera T, Yumoto $H$, Tozuka Y, Ohyashiki T. Prostaglandin E(2) induces caspase-dependent apoptosis in rat cortical cells. Neurosci Lett 2002; 317: 61.

117 Wieck A, Andersen SL, Brenhouse HC. Evidence for a neuroinflammatory mechanism in delayed effects of early life adversity in rats: relationship to cortical NMDA receptor expression. Brain Behav Immun 2013; 28: 218.

118 Kuramochi M, Nakamura S. Effects of postnatal isolation rearing and antidepressant treatment on the density of serotonergic and noradrenergic axons and depressive behavior in rats. Neuroscience 2009; 163: 448-455.
119 Plaznik A, Kostowski W, Archer T. Serotonin and depression: old problems and new data. Prog Neuropsychopharmacol Biol Psychiatry 1989; 13: 623-633.

120 Maes M, Lin AH, Verkerk R, Delmeire L, Van Gastel A, Van der Planken M et al. Serotonergic and noradrenergic markers of post-traumatic stress disorder with and without major depression. Neuropsychopharmacology 1999; 20: 188-197.

121 Nakamura S. Axonal sprouting of noradrenergic locus coeruleus neurons following repeated stress and antidepressant treatment. Prog Brain Res 1991; 88: 587-598.

122 Nakamura S, Sakaguchi T, Aoki F. Electrophysiological evidence for terminal sprouting of locus coeruleus neurons following repeated mild stress. Neurosci Lett 1989; 100: 147-152.

123 Kitayama I, Yaga T, Kayahara T, Nakano K, Murase S, Otani M et al. Long-term stress degenerates, but imipramine regenerates, noradrenergic axons in the rat cerebral cortex. Biol Psychiatry 1997; 42: 687-696.

124 Zhou L, Huang K-X, Kecojevic A, Welsh AM, Koliatsos VE. Evidence that serotonin reuptake modulators increase the density of serotonin innervation in the forebrain. J Neurochem 2006; 96: 396-406.

125 Franklin TB, Russig H, Weiss IC, Graff J, Linder N, Michalon A et al. Epigenetic transmission of the impact of early stress across generations. Biol Psychiatry 2010; 68: 408-415.

126 Yoo SB, Kim B-T, Kim JY, Ryu V, Kang D-W, Lee J-H et al. Adolescence fluoxetine increases serotonergic activity in the raphe-hippocampus axis and improves depression-like behaviors in female rats that experienced neonatal maternal separation. Psychoneuroendocrinology 2013; 38: 777-788.

127 O' Connor RM, Pusceddu MM, Dinan TG, Cryan JF. Impact of early-life stress, on group III mGlu receptor levels in the rat hippocampus: effects of ketamine, electroconvulsive shock therapy and fluoxetine treatment. Neuropharmacology 2013; 66: 236-241.

128 Hui J, Zhang Z, Liu S, Xi G, Zhang X, Teng G et al. Adolescent escitalopram administration modifies neurochemical alterations in the hippocampus of maternally separated rats. Eur Neuropsychopharmacol 2010; 20: 875-883.

129 Couto FSed, Batalha VnL, Valadas JS, Data-Franca Jo, Ribeiro JA, Lopes LsV. Escitalopram improves memory deficits induced by maternal separation in the rat. Eur J Pharmacol 2012; 695: 71-75.

130 Bessa JM, Ferreira D, Melo I, Marques F, Cerqueira JJ, Palha JA et al. The moodimproving actions of antidepressants do not depend on neurogenesis but are associated with neuronal remodeling. Mol Psychiatry 2009; 14: 764-773.

131 Manthey L, Leeds C, Giltay EJ, van Veen T, Vreeburg SA, Penninx BWJH et al. Antidepressant use and salivary cortisol in depressive and anxiety disorders. Eur Neuropsychopharmacol 2011; 21: 691-699.

132 Cotella EM, Mestres Lascano I, Franchioni L, Levin GM, Surez MM. Long-term effects of maternal separation on chronic stress response suppressed by amitriptyline treatment. Stress 2013; 16: 477.

133 Piubelli C, Gruber S, El Khoury A, Mathe AA, Domenici E, Carboni L. Nortriptyline influences protein pathways involved in carbohydrate metabolism and actinrelated processes in a rat gene-environment model of depression. Eur Neuropsychopharmacol 2011; 21: 545-562.

134 Piubelli C, Vighini M, Mathe AA, Domenici E, Carboni L. Escitalopram affects cytoskeleton and synaptic plasticity pathways in a rat gene-environment interaction model of depression as revealed by proteomics. Part II- environmental challenge. Int J Neuropsychopharmacol 2011; 14: 834-855.

135 Husum H, Mathe AA. Early life stress changes concentrations of neuropeptide $Y$ and corticotropin-releasing hormone in adult rat brain. Lithium treatment modifies these changes. Neuropsychopharmacology 2002; 27: 756-764.

136 Niculescu MD, Zeisel SH. Diet, methyl donors and DNA methylation: interactions between dietary folate, methionine and choline. J Nutr 2002; 132: 2333S-2335SS.

137 Rishi V, Bhattacharya P, Chatterjee R, Rozenberg J, Zhao J, Glass K et al. CpG methylation of half-CRE sequences creates C/EBPalpha binding sites that activate some tissue-specific genes. Proc Natl Acad Sci USA 2010; 107: 20311-20316.

138 Weaver IC, Cervoni N, Champagne FA, D'Alessio AC, Sharma S, Seckl JR et al. Epigenetic programming by maternal behavior. Nat Neurosci 2004; 7: 847-854.

139 Strahl BD, Allis CD. The language of covalent histone modifications. Nature 2000; 403: $41-45$.

140 Kao GS, Cheng LY, Chen LH, Tzeng WY, Cherng CG, Su CC et al. Neonatal isolation decreases cued fear conditioning and frontal cortical histone 3 lysine 9 methylation in adult female rats. Eur J Pharmacol 2012; 697: 65-72.

141 Levine A, Worrel T, Zimnisky R, Schmauss C. Early life stress triggers sustained changes in histone deacetylase expression and histone $\mathrm{H} 4$ modifications that alter responsiveness to adolescent antidepressant treatment. Neurobiol Dis 2012; 45: 488-498.

142 Nemeroff CB, Dunner DL, Rothbaum BO, Kornstein S, Keitner G, Keller MB et al. Differential responses to psychotherapy versus pharmacotherapy in patients with chronic forms of major depression and childhood trauma. Proc Natl Acad Sci USA 2003; 100: 14293-14296. 
143 Rush AJ, Lebowitz BD, McGrath PJ, Rosenbaum JF, Sackeim HA, Kupfer DJ et al Acute and longer-term outcomes in depressed outpatients requiring one or several treatment steps: a STARD report. Am J Psychiatry 2006; 163: 1905-1917.

144 Rush AJ, Luther JF, Shores-Wilson K, Niederehe G, Fava M, Trivedi MH et al. Bupropion-SR, sertraline, or venlafaxine-XR after failure of SSRIs for depression. $N$ Engl J Med 2006; 354: 1231-1242.

145 Lukas M, Bredewold R, Neumann ID, Veenema AH. Maternal separation interferes with developmental changes in brain vasopressin and oxytocin receptor binding in male rats. Neuropharmacology 2010; 58: 78-87.

146 Tsuda M, Yamaguchi N, Ogawa S. Early life stress disrupts peripubertal development of aggression in male mice. Neuroreport 2011; 22: 259-263.

147 Ziegler TE, Pollak SD. Early experience in humans is associated with changes in neuropeptides critical for regulating social behavior. Proc Natl Acad Sci USA 2005; 102: 17237-17240.

148 Heim C, Young LJ, Newport DJ, Mletzko T, Miller AH, Nemeroff CB., Lower CSF. oxytocin concentrations in women with a history of childhood abuse. Mol Psychiatry 2009; 14: 954-958.

149 Opacka-Juffry J, Mohiyeddini C. Experience of stress in childhood negatively correlates with plasma oxytocin concentration in adult men. Stress 2012; 15: $1-10$.

150 Garber CE, Blissmer B, Deschenes MR, Franklin BA, Lamonte MJ, Lee IM et al. Quantity and quality of exercise for developing and maintaining cardiorespiratory, musculoskeletal, and neuromotor fitness in apparently healthy adults: guidance for prescribing exercise. Med Sci Sports Exerc 2011; 43: 1334-1359.

151 Knochel C, Oertel-Knochel V, O'Dwyer L, Prvulovic D, Alves G, Kollmann B et al. Cognitive and behavioural effects of physical exercise in psychiatric patients. Prog Neurobiol 2012; 96: 46-68.

152 Mead GE, Morley W, Campbell P, Greig CA, McMurdo M, Lawlor DA. Exercise for depression. Cochrane Database Syst Rev 2009; (3): CD004366.

153 Babyak M, Blumenthal JA, Herman S, Khatri P, Doraiswamy M, Moore K et al. Exercise treatment for major depression: maintenance of therapeutic benefit at 10 months. Psychosom Med 2000; 62: 633-638.

154 Trivedi MH, Greer TL, Grannemann BD, Chambliss HO, Jordan AN. Exercise as an augmentation strategy for treatment of major depression. J Psychiatr Pract 2006; 12: $205-213$.

(i) This work is licensed under a Creative Commons Attribution cc) NonCommercial-NoDerivs 3.0 Unported License. The images or other third party material in this article are included in the article's Creative Commons license, unless indicated otherwise in the credit line; if the material is not included under the Creative Commons license, users will need to obtain permission from the license holder to reproduce the material. To view a copy of this license, visit http://creativecommons.org/licenses/by-nc-nd/3.0/ 